\begin{tabular}{|c|c|c|}
\hline Beitr. Ent. & Berlin & ISSN 0005-805X \\
\hline $\mathbf{4 8}(1998) 2$ & S. 539 & 05.10 .1998 \\
\hline
\end{tabular}

\title{
Validity of GisTEL names in the Insecta
}

\author{
DONALD B. BAKER
}

In a recent treatment of the Apoidea described by J. N. F. X. GISTEL (BAKER 1997) it was indicated that the International Commission on Zoological Nomenclature would be invited to use its plenary powers to suppress for nomenclatural purposes 16 names identified in that paper [p. 333, Recommendation, (3)] as nomina dubia.

The matter was, accordingly, referred to the Secretariat of the Commission. The Executive Secretary (Dr. P. K. TUBBS, in litt., 18 December 1997) replied that no ruling by the Commission was necessary: since, with the exception of Colletes nigricans, Gistel's names in the Apoidea were either unassignable to taxa [the 16 names designated as nomina dubia] or were junior to names is use, none of them posed any nomenclatural problem. He added that the forthcoming new edition of the Code of Zoological Nomenclature, to come into effect on 1 January 1999, would prescribe that names in general current use would automatically [i.e., without a Commission ruling] take precedence over names not used since 1899. Consequently, Gistel names that have not been used since that date may not be revived, except in the remote likelihood that they should be found to apply to taxa for which no valid name existed. The revised Code will clearly resolve the problem of the much greater number of ignored Gistel names in groups other than the Apoidea, to which group the author' previous note primarily related.

\section{Reference}

BAKer, D. B. 1997: The Apoidea described by Johannes Nepomuk Franz XAVer Gistel (Insecta: Hymenoptera). - Beit. Ent. 47(2): 327-336.

Author's address:

Dr. DONALD B. BAKER

Hope Entomological Collections,

University Museum of Natural History,

Oxford OX1 3PW

U.K. 